\title{
A note on the history of the four-colour conjecture
}

\author{
Brendan D. McKay \\ Research School of Computer Science \\ Australian National University \\ Canberra, ACT 0200, Australia \\ bdm@cs.anu .edu.au
}

\begin{abstract}
The four-colour conjecture was brought to public attention in 1854, most probably by Francis or Frederick Guthrie. This moves back by six years the date of the earliest known publication.
\end{abstract}

As the most famous problem in discrete mathematics, the four-colour problem has been the subject of much historical as well as mathematical investigation. We refer to the surveys of this history in two excellent recent books [3, 7].

As the early history is understood, Francis Guthrie communicated the problem to his brother Frederick, who in turn showed his teacher Augustus De Morgan. In what remains the earliest known document, De Morgan wrote of the problem to Hamilton on the same day that he heard it, October 23, 1852. Some additional private correspondence is known from the following few years, but it has been believed that the first publication of the problem was in an anonymous book review by De Morgan in the magazine The Athencum in 1860 [2].

However, there was an earlier appearance in the same magazine, apparently overlooked until now. On June 10, 1854, a letter appeared in the Miscellanea section of The Athenceum [4]. Printed in smaller type than the surrounding text, it read in full:

Tinting Maps.-In tinting maps, it is desirable for the sake of distinctness to use as few colours as possible, and at the same time no two conterminous divisions ought to be tinted the same. Now, I have found by experience that four colours are necessary and sufficient for this purpose,--but I cannot prove that this is the case, unless the whole number of divisions does not exceed five. I should like to see (or know where I can find) a general proof of this apparently simple proposition, which I am surprised never to have met with in any mathematical work.

F. G.

The magazine does not identify "F. G.", but the short period of time between this letter and the known interaction between Francis and Frederick Guthrie makes it highly 
Tinting Maps.-In tinting maps, it is desirable for the sake of distinctness to use as few colours as possible, and at the same time no two conterminous divisions ought to be tinted the same. Now, I have found by experience that four colours are necessary and sufficient for this purpose,but I cannot prove that this is the case, unless the whole number of divisions does not exceed five. I should like to see (or know where I can find) a general proof of this apparently simple proposition, which I am surprised never to have met with in any mathematical work. F. G.

Figure 1: Letter in The Athencum of June 10, 1854.

likely that one of them was responsible. It doesn't seem possible to identify which of the brothers it was, but I favour Francis for the following, inconclusive, reason. In 1880, Frederick carefully attributed the discovery to Francis and did not mention having studied the problem himself [5]. This does not seem consistent with him having written a 1854 letter that takes all the credit for it.

An intriguing, but highly conjectural, possibility is that "F. G." was Francis Galton. At the time, Galton was famous for his explorations in Africa, and later he wrote about the art of map making [1]. However, between the 1854 letter of "F. G." and the earliest proven connection between Galton and the four-colour problem lie more than 20 years [1].

The letter is also of interest in that "F. G." admits he can't solve the problem. This is at variance with Frederick's 1880 testimony that Francis had a proof in 1852 even though it "did not seem altogether satisfactory to himself" [5]. As we know, De Morgan in his 1860 article believed he was presenting sufficient justification to his readers, while in reality he was only observing that $K_{5}$ is non-planar.

The library of City University London holds a "marked copy" of The Athenceum on which the editors wrote the identities of many of the anonymous contributors [6]. Unfortunately, the identity of "F. G." is not indicated there. However the author or editor of the Miscellanea section that includes the letter of "F.G." is indicated. The unclear handwriting probably reads "Winton", who remains unidentified.

Robin Wilson made useful comments on the first draft of this note. Thanks also to Micheline Beaulieu, Norman Biggs, Colin Burrow, Tony Crilly, Keith Lloyd, and Sheila Munton.

\section{References}

[1] Tony Crilly, Arthur Cayley FRS and the Four-Colour Map Problem, Notes and Records of the Royal Society of London, 59 (2005) 285-304. 
[2] Augustus De Morgan (anonymous), The Philosophy of Discovery, Chapters Historical and Critical, The Athencum, 1694 (April 14, 1860), 501-503.

[3] Rudolf Fritsch and Gerda Fritsch, The Four-Color Theorem: History, Topological Foundations, and Idea of Proof, trans. J. Lie Peschke, Springer, 1998.

[4] "F. G", Tinting Maps, The Athencum, 1389 (June 10, 1854), 726.

[5] Frederick Guthrie, Note on the Colouring of Maps, Proc. Royal Soc. Edin., 10 (1880) $727-728$.

[6] Michelline Hancock-Beaulieu and Sue Holland, Indexing The Athenaeum: aims and difficulties, The Indexer, 17 (1991) 167-172.

[7] Robin Wilson, Four Colours Suffice: How the Map Problem was Solved, Allan Lane, 2002. 